\begin{abstract}
This paper evaluates the link between the diffusion of electricity and the increase in labour productivity growth in the manufacturing sector during the inter-war period. A comparative analysis of the USA, Britain, Germany, and Japan shows that the trend acceleration in labour productivity is common to all these countries except Germany and is correlated with electricity diffusion. Germany's labour productivity growth was nevertheless sustained in 1925 - 1938. The USA saw an earlier acceleration because the diffusion of electricity-based general-purpose technologies in production was much faster than in the other countries examined.
\end{abstract}

KEY WORDS: Economic Growth, Economic History, Productivity, Long Swings JEL CLASSIFICATION: N11, N12, N13, N14, N60, O40 


\title{
Electricity diffusion and Trend Acceleration in Inter-War Manufacturing Productivity ${ }^{1}$
}

\author{
Cristiano Andrea Ristuccia \\ Department of Applied Economics \\ Austin Robinson Building \\ Sidgwick Avenue \\ Cambridge CB3 9DE \\ UK \\ Solomos Solomou \\ Faculty of Economics \\ Austin Robinson Building \\ Sidgwick Avenue \\ Cambridge CB3 9DD \\ UK
}

February, 2002

\section{INTRODUCTION}

The considerable acceleration in TFP growth in the US in the 1920s has been associated with a substantial increase in labour productivity and a concurrent fall in capital intensity in the US manufacturing sector (David and Wright 1999a; David and Wright 1999b). According to this interpretation, the increase in labour productivity and the concurrent fall in capital intensity were the direct results of the diffusion of electricity-based general purpose technologies in production, and of the supply shock to the labour market caused by increasing restrictions on massimmigration. $^{2}$

\footnotetext{
${ }^{1}$ Research for this paper has been supported by a Research Grant from the ESRC (No. L138 25 1045). We would like to thank Adam Tooze for his collaboration in collecting the German data. Jonathan Köhler, and Adam Tooze provided useful comments on a previous version of the paper. We thank them for their help. The usual disclaimer applies.

${ }^{2}$ The link between post-WW1 US factory electrification and the observed fall in capital intensity had been previously made by Du Boff 1964, pp. 159 - 182 .
} 
It is uncontroversial that the diffusion of electric unit-drive $e^{3}$ allowed a substantial deceleration in the pace of capital accumulation. Electric unit-drive introduced substantial savings in power transmission capital (shafts and belts), and reduced the costs in the construction of industrial buildings reducing the need for multi-storey reinforced factory structures, capable of supporting the weight of machinery while minimising the distance of each piece of machinery from the source of mechanical power (David and Wright 1999a). It also allowed higher utilisation rates for existing capital through reducing the disruption to production caused by machinery downtime for repairs (ibid.), while easing the need for duplicate machinery. Moreover, it favoured the widespread transformation in factory organisation from primarily functional machinery layouts (by type of operation), to layouts in which machinery was placed according to the sequence of productive operations and to the material flows, thus reducing the necessity of holding large inventories of intermediate goods. And, importantly, the diffusion of unit-drive, and of electrical technologies in general, increased the reliance on bought electricity as a source of power in the manufacturing sector. Given the scale economies typical of a volume production process such as electricity generation, the consequent drastic reduction in power generation capital at the factory level was much faster than the corresponding increase in the generation capital of electric utilities, which was necessary to supply substitute power to the manufacturing sector (Du Boff 1967). The link between electrification and fall in capital intensity was particularly clear in the diffusion of the unit-drive system run on purchased electricity. The switch from self-generated mechanical or electric power to purchased electricity meant that, at the factory level, the supply of power automatically matched the effective demand at any one time. It also meant reducing the discrepancy between the fixed capital necessary to provide sufficient generating capacity at peak loads and the capital necessary to guarantee the typical power demand. This resulted from the fact that electricity providers were better placed to reduce the variance of the electricity demand schedule they faced than most of their industrial customers. This induced a substantial reduction in fixed capital outlays per unit generated. ${ }^{4}$ Moreover, the unitdrive system proved very efficient in terms of power use, as it allowed, by virtue of disaggregation, a better match between the power demanded by machinery and the power effectively used for machining purposes. Other things being equal, unit-drive run on purchased electricity reduced both the average and the variance of the power demand schedule, thus reducing the fixed capital outlays in power generation per unit of output.

In the light of these changes the upward shift in labour productivity in the US manufacturing sector after the First World War has been partly accounted for by the

\footnotetext{
${ }^{3}$ The system by which each machine tool is driven by a separate electric engine transforming electric energy into motive power.

${ }^{4}$ Hannah 1979, pp. $19-21$. For a discussion of some factors favouring private generation over purchases of electricity in some industrial sectors see ibid., pp. 173 - 182.
} 
effect of the diffusion of electricity ${ }^{5}$, and, in particular, by the diffusion of unit-drive electric motors. The reliability of electric motors meant that less time was wasted in repairs of power supply machinery (including power generation and power distribution apparatuses). Their modularity meant that machine tools stoppages could be localised and circumscribed to a single production unit, thus vastly reducing the time spent idle by the operators of adjacent machinery. Moreover, the power efficiency of the electric motor allowed a considerable reduction in production costs that brought about a decrease in prices and a corresponding increase in output. The reorganisation of production lines allowed by electric unit-drive produced significant savings in handling costs, largely in the form of a dramatic reduction in the material movements within the factory and a corresponding fall in the labour force occupied in transferring semi-manufactured goods and other materials between machining positions. Cheap electrical illumination allowed industrial establishments to operate safely for longer hours, increasing the intensity of utilisation of capital and therefore reducing the fixed cost of capital, prices, and ultimately increasing output. Finally, the sheer versatility of unit-drive created the conditions for the widespread introduction of scientific management techniques and practices intended to increase labour productivity.

The choice of focusing on the manufacturing sector is based on the evidence that the 1920s increase in US labour productivity originated almost entirely in the manufacturing sector. This surge in labour productivity in the manufacturing sector was common to all manufacturing industries and accounted for a large part of the increase in TFP observed in the first part of the interwar years. David and Wright (2002) suggested that the electricity diffusion framework is relevant in a comparative setting and describe the growth experience of Japan and Britain during the interwar period in terms of this hypothesis.

In this paper we build a data set that allows us to extend and evaluate the framework of David and Wright by providing quantitative evidence on the comparative experience of the US, Britain, Germany and Japan. The implicit assumption made is that the diffusion of electricity-related innovation would necessarily produce a substantial labour productivity surge concentrated in the manufacturing sector due to the inherent characteristics of the dynamo revolution. Therefore, any effect of the diffusion of these technologies would show in an increase in labour productivity in the manufacturing sector ${ }^{6}$.

\footnotetext{
${ }^{5}$ David and Wright consider the reduction in mass-immigration as the second main contributory factor to the increase in US labour productivity in the 1920s. This drastic reduction in immigration flows resulted in a large increase in the cost of labour. In turn this prompted more selective hiring methods, a higher reliance on modern labour management techniques, a new emphasis on training and human capital development and a high wage society that introduced clear incentives for the increase of work effort. In this paper we focus on developing a quantitative analysis of manufacturing labour productivity and on its links with the electricity diffusion process.

${ }^{6}$ Implicitly we are assuming that electricity diffusion should produce an increase in labour productivity with the following characteristics: (a) it should be stark; (b) it should be particularly noticeable in the manufacturing sector; (3) it should be evenly distributed among the various
} 
There are three new strands in our analysis. First, we evaluate the extent of long-term shifts in labour productivity. The magnitude of trend-acceleration is ascertained by decomposing trends and cycles in labour productivity. Secondly, we provide quantitative evidence on electricity diffusion for a wider number of countries. Finally, we mainly work with census data relating to the entire manufacturing sector. This allows us to better pinpoint the comparative extent and nature of electricity diffusion while doing away with the risks inherent in generalising the results from case studies and anecdotal evidence. The paper is structured as follows; section 1 describes and analyses the data on labour productivity in the manufacturing sector; section 2 provides data on the diffusion of electricity in these countries. Section 3 provides a discussion of our results and draws some general conclusions.

\section{Labour Productivity Trends in MAnufaCturing}

\section{USA}

Figure 1: USA Manufacturing Labour Productivity 1889-1938

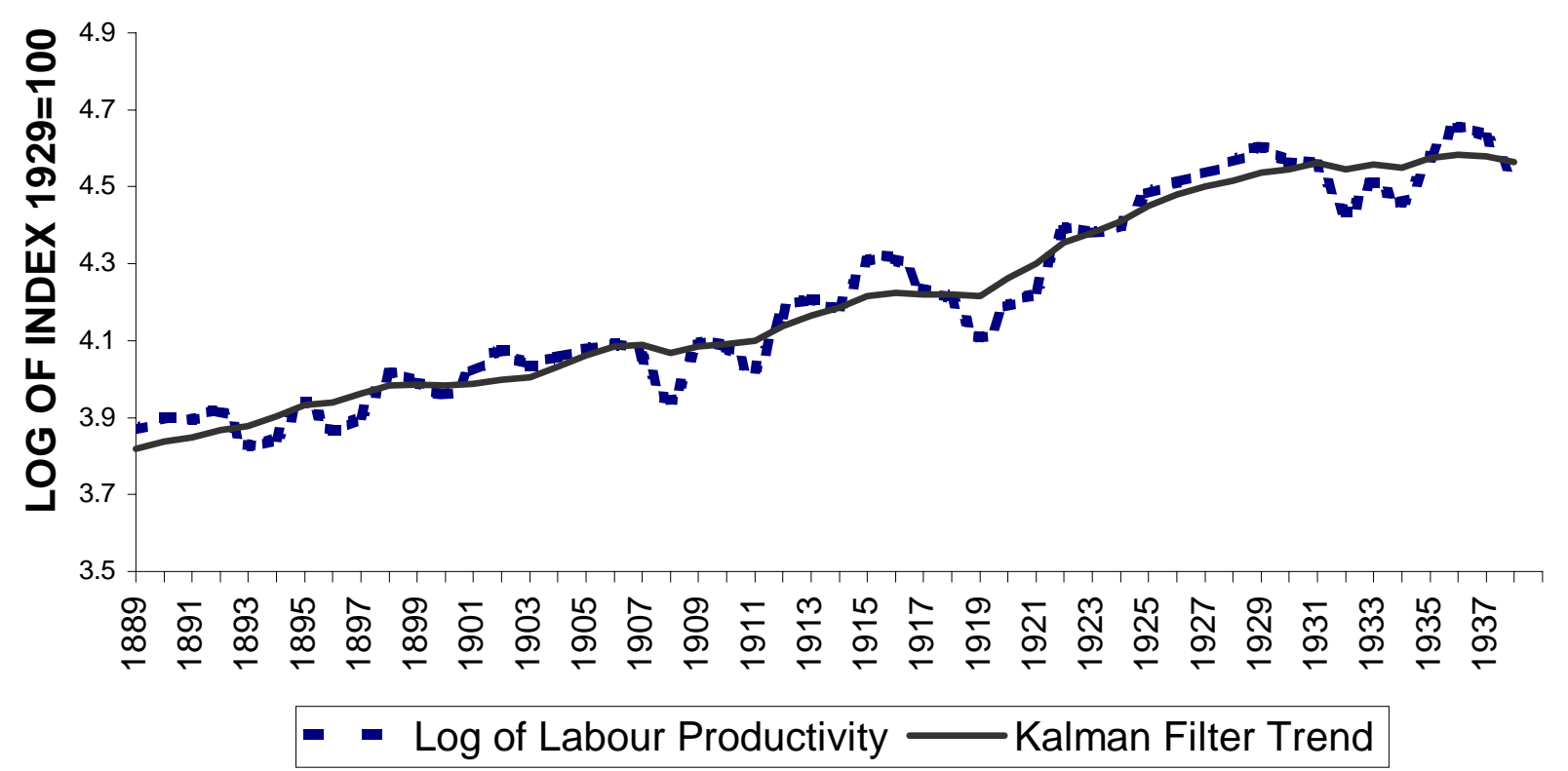

Figure 1 plots the path of labour productivity in the US manufacturing sector using

manufacturing industries. All these characteristics are confirmed by David and Wright (2002) for Britain during the 1929- 1937. 
annual data over the period 1889-1938. This logarithmic path suggests that the decade of the 1920s was a decade of significantly accelerated growth rates. The rate of growth of labour productivity averaged 5 per cent per annum during 1920-29. However, given the cyclical nature of American economic growth some care is needed to capture the extent and timing of the observed trend acceleration. To do so we will consider the data from a number of angles. Table 1 calculates the geometric growth rates for a number of long period comparisons. US labour productivity growth before 1913 is best depicted as a series of long swings (Abramovitz 1961, Abramovitz 1968), representing periods of accelerated and retarded economic growth. The acceleration of growth rates observed during 1900-1913 relative to $1889-1900$ is mainly cyclical in nature.

Table 1: Labour Productivity Growth in US Manufacturing (Per cent growth per annum)

\begin{tabular}{ccc}
\hline \hline & & INTER-PERIOD \\
& GROWTH RATE & GROWTH CHANGE \\
\hline \hline $1869-1879$ & 0.0072 & - \\
$1879-1889^{7}$ & 0.0220 & 0.0148 \\
$1889-1900$ & 0.0085 & -0.0135 \\
$1900-1913$ & 0.0189 & +0.0104 \\
$1913-1929$ & 0.0250 & +0.0061 \\
$1929-1938$ & -0.0086 & -0.0336 \\
\hline \hline
\end{tabular}

This long swing pattern of US productivity growth underwent significant changes in the period 1913-29. Average growth rates began to display some trend acceleration during c.1913-29. Working with a long swing phasing of US economic growth will allow us to control for some of these effects. Taking growth measures over complete swings illustrates this segmentation of productivity growth. Labour productivity growth averaged 0.0146 during the complete swing of 1869-1889 and 0.0132 during 1889-1906. However, during 1906-1929 and 1913-29 growth rates averaged 0.0224 and 0.025 respectively. Clearly we observe a non-cyclical acceleration of labour productivity growth of approximately 0.01 per annum during these inter-period comparisons.

Formal statistical analysis of the labour productivity data suggests that the path of labour productivity is stochastic. In order to describe these stochastic changes we employ a Kalman filter model of trend-cycle decomposition over the period 1889-1938. This method of trend-cycle decomposition is outlined in an appendix to this paper and the trend estimate is presented in Figure 1. This analysis

\footnotetext{
${ }^{7}$ The pre-1889 data are based on the benchmark years of 1869,1879 and 1889.
} 
illustrates two features that are noteworthy. First, there are a number of stochastic steps in the data for productivity and secondly, the 1920s also display a high cyclical gain in labour productivity.

Figure 2: Kalman Filter Estimate of the Growth rate of US Labour Productivity (1889-1972)

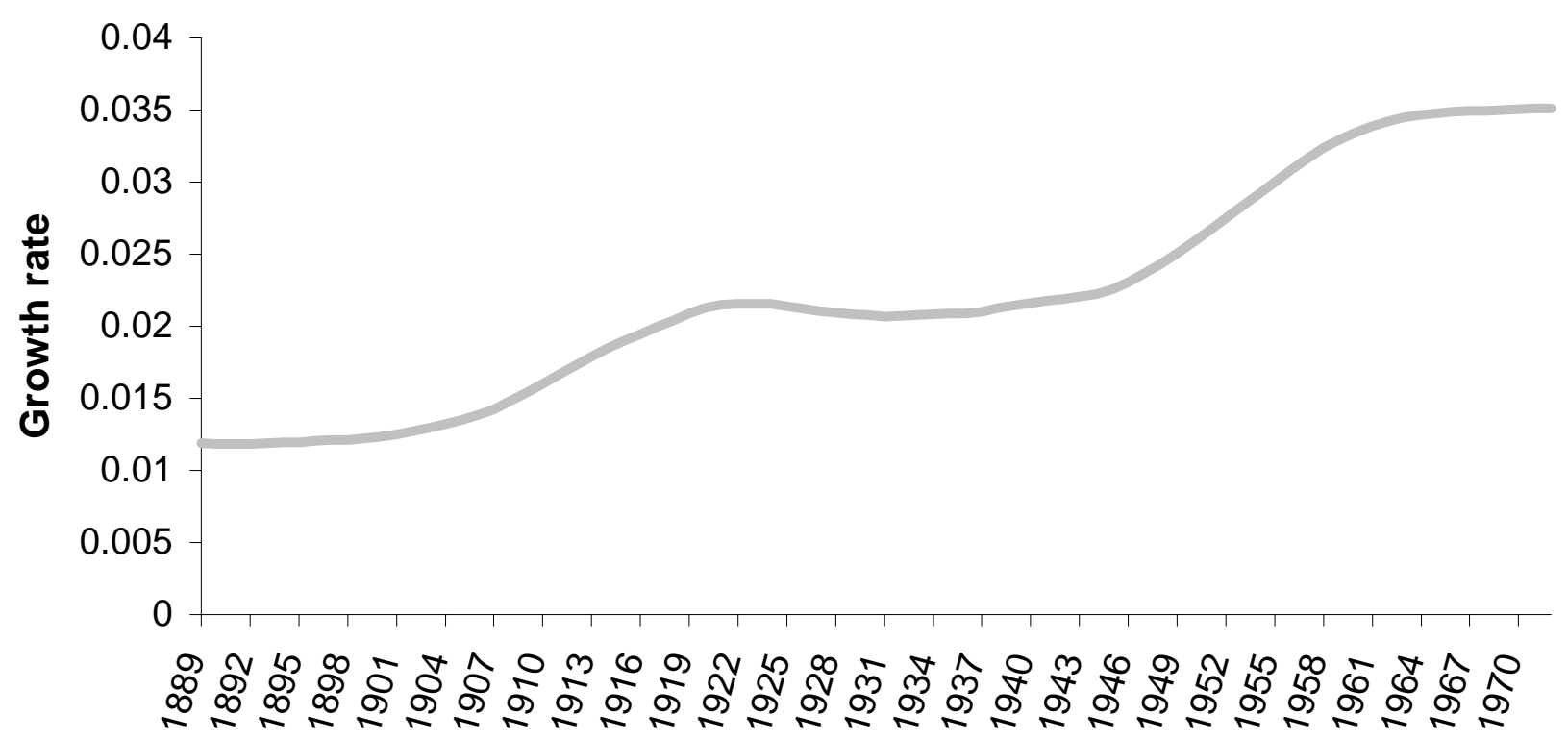

Such time series methods provide more robust descriptions with more data observations. To evaluate the sensitivity of this description we also derive the Kalman filter decomposition of trend and cycles over the period 1889-1972 (see Figure 2). As with the shorter sample the trend is stochastic. The longer time period allows us to distinguish a stochastic shift to the growth rate of labour productivity. The period 1906-1924 represented a phase of trend acceleration, whilst the period after 1924 saw a plateau on a higher growth rate.

\section{BRITAIN}

Figure 3 plots British manufacturing sector labour productivity during 1869-1938. The trend in manufacturing sector labour productivity was relatively stable during 1870-1913 (around an average growth rate of 0.0124). A Kalman filter trend-cycle decomposition suggests that the only episodic growth variations that stand out are swings in labour productivity growth of approximately 20 years with upswings in the $1870 \mathrm{~s}$ and 1890s and downswings in the 1880s and the 1900s. These cyclical movements are captured in Table 2. 
Figure 3: British Manufacturing Labour Productivity

1869-1938

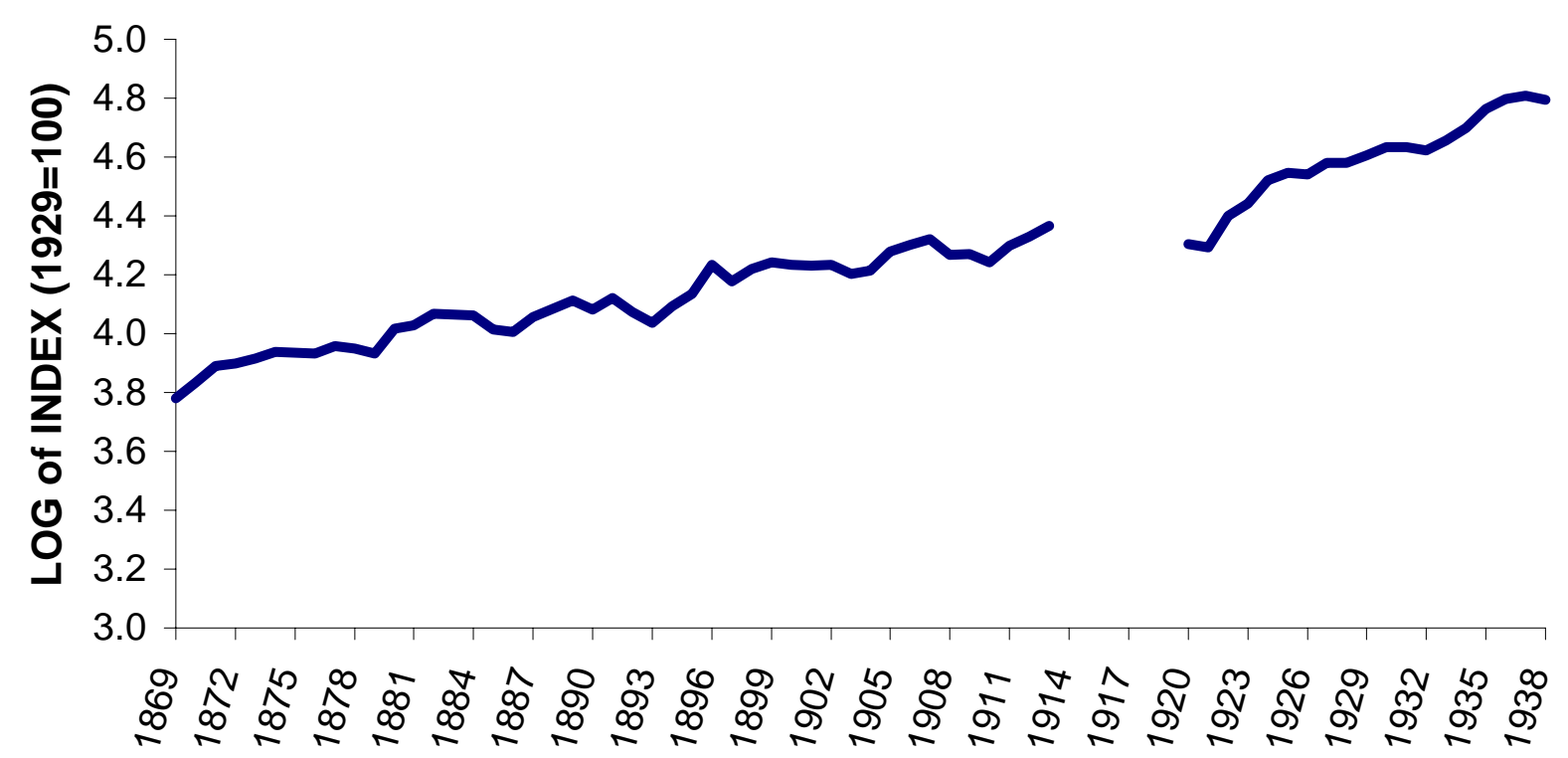

Table 2: Labour Productivity Growth in British Manufacturing (Per cent growth per annum)

\begin{tabular}{ccc}
\hline & & INTER-PERIOD \\
& GROWTH RATE & GROWTH CHANGE \\
\hline $1871-1881$ & 0.0139 & - \\
$1891-1891$ & 0.0093 & -0.0046 \\
$1891-1900$ & 0.0126 & +0.0033 \\
$1900-1910$ & 0.0080 & -0.0046 \\
\hline \hline
\end{tabular}

During the inter-war period a discontinuity began to emerge in the trends of manufacturing sector labour productivity relative to the pre-1913 era. Over the period 1920-38 the mean growth rate of labour productivity more than doubled relative to the pre-1913 period. Some of this rapid growth reflects catch-up on the poor performance of the trans-war years, but a component of it is best depicted as trend acceleration. 
Table 3: Labour Productivity Growth in British Manufacturing 1870-1937 (Per cent growth per annum)

\begin{tabular}{|c|c|c|}
\hline & GROWTH RATE & $\begin{array}{c}\text { INTER-PERIOD } \\
\text { GROWTH CHANGE }\end{array}$ \\
\hline $1870-1913$ & 0.0133 & - \\
\hline 1913-1929 & 0.0149 & +0.0016 \\
\hline 1929-1937 & 0.0254 & +0.0105 \\
\hline
\end{tabular}

Manufacturing labour productivity growth began to accelerate in the inter-war period relative to the past. Rates of growth began to display trend acceleration in the late 1920s and this process continued at an accelerated pace during the 1930s. During the peak to peak cycle phases of 1924-29 and 1929-37 growth of manufacturing sector labour productivity averaged 0.0167 and 0.0254 respectively.

Comparing Britain with America suggests a number of important differences in the temporal movements of labour productivity gains. Significant differences are observed in the pre-1924 episode. Whilst the USA had seen a major labour productivity surge during 1906-1924, Britain failed to match these gains. In contrast, Britain continued to make significant labour productivity gains during the 1930s. Such temporal differences offer useful information when analysing the role of electricity in productivity growth.

\section{JAPAN}

An index for Japanese labour productivity in the manufacturing sector has been constructed on the basis of the employment data contained in Umemura et al. 1988, and of the output of the Japanese manufacturing industry over the period 1896-1938 taken from the Japanese historical national accounts (Unemura et. al. 1988, and Shinoara 1972). This is depicted in Figure $4 .^{8}$

\footnotetext{
${ }^{8}$ The data overlap in 1919 and 1920 allowing us to scale the pre-1919 series to be comparable to the interwar series. The employment data were estimated on the basis of annual surveys of establishment with more than nine employees before 1919, of establishments with more than four employees for the period 1919 - 1937, and for all establishments from 1938 onwards. The extrapolation for the smaller establishments before 1938 and the coverage of the State-owned establishments were originally obtained using industrial census information and more comprehensive local surveys when available.
} 
Figure 4: Japan Manufacturing Labour Productivity 1896-1940

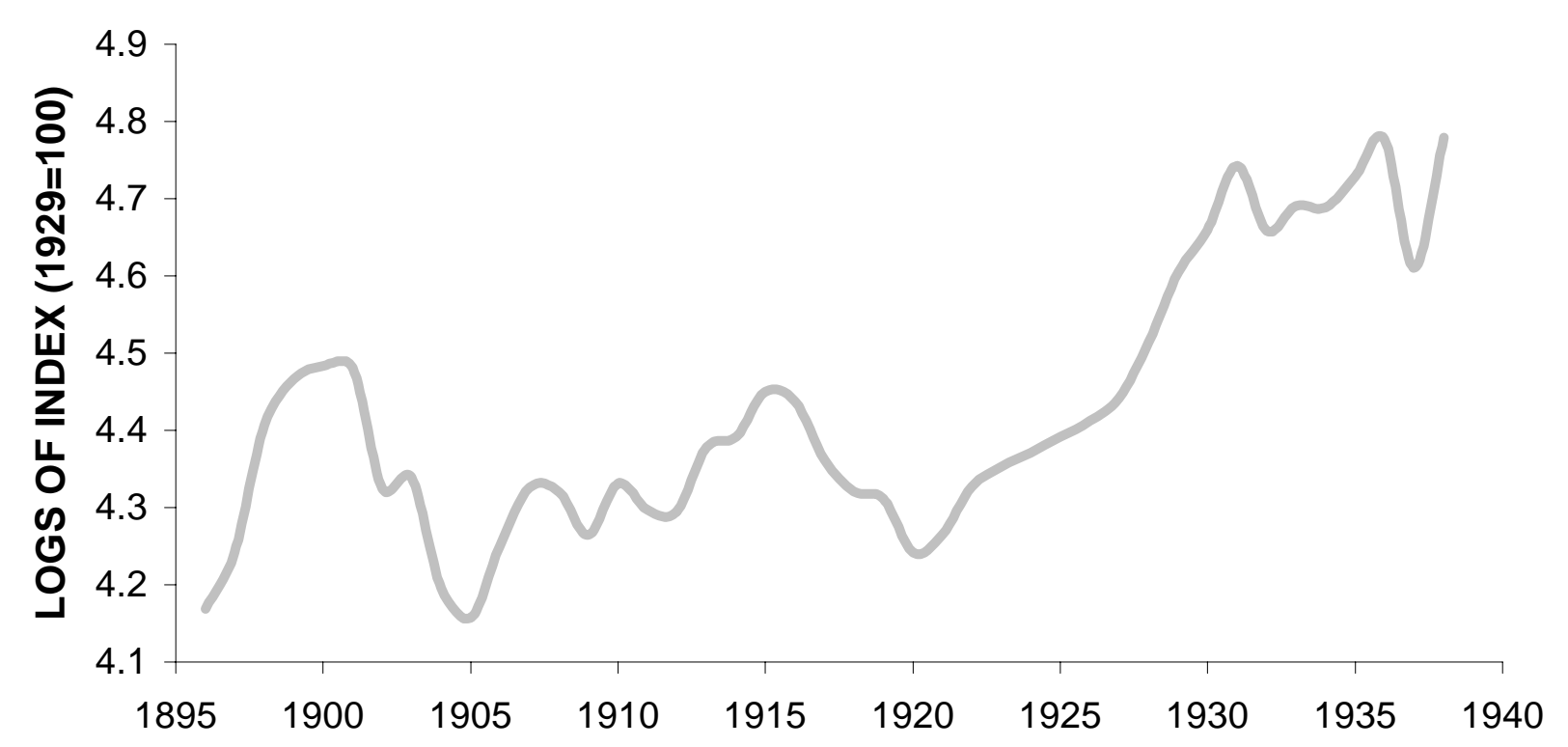

Sources. Our calculations on data from Umemura et al. 1988, Table 18, p. 243, Table 19 p. 256, and notes at p. 164; and Shinohara 1972, Table 2, pp. $144-147$, and notes at p. 132.

Japan's manufacturing sector showed a labour productivity growth rate of 0.0172 per annum over the period 1896-1940. Labour productivity fluctuated significantly about this average growth, partly reflecting the long swings in manufacturing output. Using the phases of growth outlined for manufacturing output, the following pattern of growth is observed:

Table 4: Labour Productivity Growth in Japan's Manufacturing (Per cent growth per annum)

\begin{tabular}{ccc}
\hline & INTER-PERIOD \\
& GROWTH RATE & $\begin{array}{c}\text { INOWTH CHANGE } \\
\text { GROWTH }\end{array}$ \\
\hline $1898-1908$ & 0.0072 & - \\
$1908-1916$ & 0.0146 & 0.0074 \\
$1916-1927$ & 0.0041 & -0.0105 \\
$1927-1938$ & 0.0307 & 0.0266 \\
\hline \hline
\end{tabular}

Longer-term growth comparisons suggest segmentation in the path of labour productivity growth in the late 1920s and 1930s. By the 1930s Japan's manufacturing labour productivity growth rate had increased threefold relative to its long-term trend, irrespective whether we measure over complete swings or longer periods (see Table 5). 
Table 5: Labour Productivity Growth in Japan's Manufacturing (Per cent growth per annum)

\begin{tabular}{ccc}
\hline & GROWTH RATE & $\begin{array}{c}\text { INTER-PERIOD } \\
\text { GROWTH CHANGE }\end{array}$ \\
\hline \hline $1896-1927$ & 0.0088 & - \\
$1927-1938$ & 0.0307 & 0.0219 \\
& & \\
$1908-1927$ & 0.0067 & - \\
$1927-1940$ & 0.0371 & 0.0304 \\
\hline \hline
\end{tabular}

\section{GERMANY}

Figure 5 plots the path of (log) labour productivity in German manufacturing sector using annual data over the period 1885-1938 (with gaps over the trans-war period 1914-24). Some benchmarked data for the period 1875-1885 also exist. Inspection of the trend of the pre-1913 period and the interwar period does not suggest that the inter-war period was one of trend accelerated growth rates. Growth rates of manufacturing sector labour productivity were high, averaging 0.0281 over 1925-38 and 0.0207 during 1885-1913, but were not high enough to fully catch up from the poor productivity growth of the trans-war period.

Figure 5: German Manufacturing Sector Labour Productivity 1875-1938

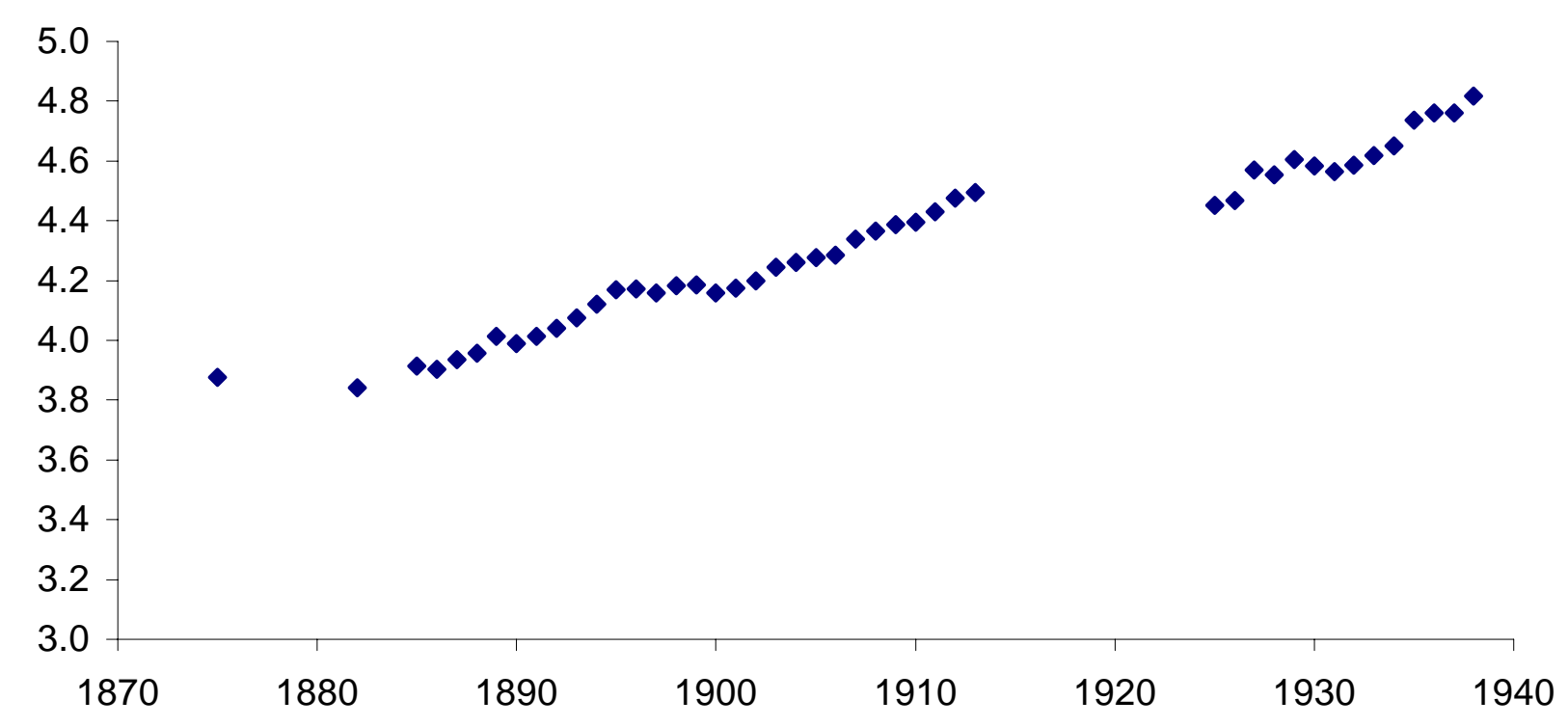


Table 6 calculates the geometric growth rates for a number of long period comparisons. The benchmark data for the period 1875-1885 is included to allow us an initial reference point. Including this observation suggests that labour productivity growth before 1913 is best depicted as following a series of episodes of slow and fast rates of growth.

Table 6: Labour Productivity Growth in German Manufacturing (Per cent growth per annum)

\begin{tabular}{lll}
\hline \hline & GROWTH RATE & $\begin{array}{l}\text { INTER-PERIOD } \\
\text { GROWTH CHANGE }\end{array}$ \\
\hline \hline $1875-1885^{9}$ & 0.0038 & - \\
$1885-1895$ & 0.0257 & +0.0219 \\
$1895-1902$ & 0.0040 & -0.0217 \\
$1902-1913$ & 0.0269 & +0.0229 \\
$1913-1925^{10}$ & -0.0036 & -0.0305 \\
$1925-1929$ & 0.0385 & +0.0421 \\
$1929-1938$ & 0.0234 & -0.0151 \\
\hline \hline
\end{tabular}

Working with a long swing phasing of German productivity growth will help to clarify this point. Taking growth measures over complete swings illustrates this segmentation of productivity growth. Labour productivity growth averaged 0.0180 during the complete swing of 1895-1913 and a similar rate over 1875-1895. During 1913-29 and 1913-38 growth rates averaged 0.0069 and 0.0129 respectively. Clearly we observe an inability to return to pre-1913 trends.

Germany stands in marked contrast to all the other countries considered here. The results imply that the trans-war shocks were so large that the observed labour productivity growth of the inter-war epoch was not able to shift the long-term productivity performance of the German manufacturing sector. Another perspective on interwar growth rates is to compare the observed labour productivity growth rate of the inter-war period with other episodes of high growth. This is done in Table 7. Given the variance of annual growth rates the inter-war mean growth rate is indistinguishable in magnitude from earlier high growth episodes of comparable duration.

\footnotetext{
${ }^{9}$ The pre-1885 data are based on the benchmark years of 1875,1882 and 1885 .

${ }^{10}$ The calculation is based on the benchmark years of 1913 and 1925.
} 
Table 7: Labour Productivity Growth in German Manufacturing: Comparing High Growth Episodes (Per cent growth per annum)

\begin{tabular}{ll} 
& GROWTH RATE \\
\hline \hline $1925-1938$ & 0.0281 \\
$1885-1895$ & 0.0257 \\
$1902-1913$ & 0.0269 \\
\hline
\end{tabular}

Summarising, prima facie evidence suggests that the growth rates of US labour productivity accelerated during the period 1906-1929. Formal analysis suggests that most of this acceleration was concentrated in the period 1906-24, although the economy settled on this higher rate after about 1924, once we control for the cyclical effects observed in the 1920s and 1930s. Comparing British trends with American highlights some significant differences. During 1913-24 labour productivity in the UK saw a pause in growth. During the late 1920s we observe significant labour productivity gains, but these were not large enough to shift the long-term path of the economy. By the 1930s, there is a significant acceleration in labour productivity growth rates compared to the past. A comparison of US-UK labour productivity ratios shows that while in the period 1890 - 1913 US labour productivity remained more or less stable at a level twice as high as that of the UK, by 1922 it had reached a level of 2.5 that of the UK. Thereafter this ratio plateaued around this level until the end of the decade. By the 1930s the US labour productivity had returned to be twice as high as that of the UK. Comparing Japan and the USA also highlights a major difference of path during the 1920s and 1930s. As in the case of the UK, in Japan the major long-term productivity gains were made in the late 1920s and 1930s.

In the case of Germany, we do not observe trend acceleration in the period 1925-1938. The growth of labour productivity in the German manufacturing sector in this period is best described as an episode of high growth. However, the average growth rate of labour productivity in this period is statistically indistinguishable from that of previous high-growth episodes (given the high variance in annual growth rates). Although high, the labour productivity growth rate was insufficient to return to the pre-war trend and make-up for the trans-war losses. In this respect Germany stands apart from the experience of the other three countries.

\section{THE Adoption OF Electricity IN THE MANUFACTURING SECTOR}

If the take-up rate for electricity-based technologies in the manufacturing sector is to be considered a primary factor in explaining cross-country differences in labour productivity growth rates, it has to show substantial variations from country to country. Therefore the first question to be answered is the following: was the take- 
up rate for electricity-based technologies in the manufacturing sector noticeably different in the US from that of its main competitors? Comparative data which could answer this question are few and far between.

The traditional indicator of the extent of electrification of production has been the capacity of primary electric motors. These are motors driven by electricity purchased from utilities and, therefore, not produced within the plant. An indicator of the extent of electrification of production in the manufacturing sector that is directly linked to labour productivity is the capacity (in $\boldsymbol{H P}$ ) of primary electric motors per employee. Data on primary electric capacity is relatively easy to find, but it should be noted that such an indicator has serious drawbacks as a means of thinking about the effects of the electrification of production methods. There are two main problems. First, electric motors were not necessarily employed at the same rate in two countries. This problem is clearly exemplified by the number and length of shifts over which industrial machinery is operated in one day. If in one country factories typically operate two working-shifts of ten hours and in another they typically operate on three working shifts of eight hours, then capacity measures per employee would not be directly comparable. Secondly, the existence of secondary electric motors (those run on electricity produced within the industrial establishment), introduce a further element of confusion in the comparative exercise. Traditionally $\boldsymbol{H P}$ capacity data has been collected with a view to thinking about the mechanisation process and secondary electric motors have generally been excluded from capacity computations on the basis that they add no inanimate power capacity to production. In this context, adding secondary electric motors would introduce a certain amount of double counting. For example, including secondary electric motors would mean counting both the horse power capacity of a steam turbine attached to an electric generator within the plant, and the horse power capacity of all the electric motors that use the electricity so generated to run production machinery in the factory. Clearly if the problem is to ascertain the sources of power on which the factory is run then this double counting is highly inappropriate. Yet, this is by no means the case when studying the effect of the availability of electric production machinery on labour productivity. Here the fact that the electricity employed to run production machinery is bought from an external supplier or produced within the industrial establishment is immaterial. Counting only primary electric motors might be partially justified on the basis that running production machinery on bought electricity became increasingly common in the period, as it proved to produce substantial cost reductions. More pragmatically, data availability has been another factor in favour of a comparison of primary electric motor capacity per employee in the manufacturing sector. In figure 6 , we present the data for this indicator in the US, Japan, and the UK. 
Figure 6: Electric capacity (primary electric motors) per employee in the manufacturing sector.

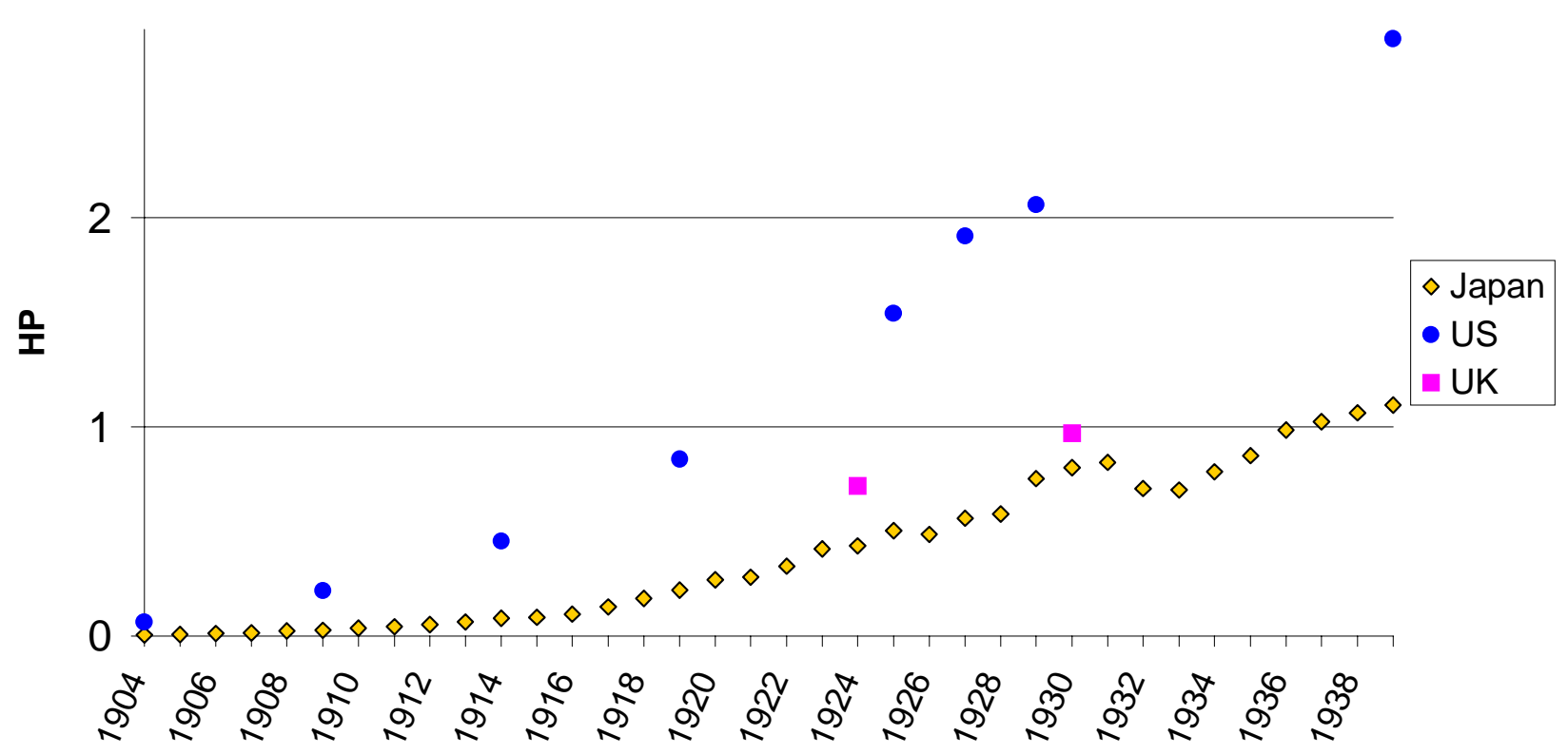

Sources.

Employment: US - Kendrick 1961, Table D-II, pp. 465 - 466 and Table D-VII p. 488; Japan Umemura et al. 1988, Tables 18 and 19 pp. 242 - 256; UK - Board of Trade; Business Statistics office, Census of Production: Final Report, (censuses 1924, 1930). Primary electric capacity: US - Bureau of the Census, Historical statistics of the United States. Colonial times to 1970. Part 2 (1975), Series P71, p. 681; Japan - Minami 1965, Table 27, p. 223; UK - Board of Trade; Business Statistics office, Census of Production: Final Report, (censuses 1924, 1930). Notes: Data for the UK are relative to the manufacturing sector proper and the manufacturing establishments run by Government Departments (mostly the naval shipyards and the ordnance factories). Data of the 1924 census refer to all the manufacturing companies in the UK, while those of the 1930 census refer only to factories in Great Britain with more that ten employees (including the working owner), and to factories with more than five employees (including the working owner) in Northern Ireland.

It should be noted that the lack of data for the secondary electric engines in the Japanese manufacturing sector should not dramatically change the picture of a substantially higher - and increasingly so - electric capacity at the disposal of the typical US manufacturing worker as compared to his/her Japanese counterpart in the interwar period. In fact, omitting secondary electric motors from the comparison produces a bias in the sense of underestimating the disparity between the US and Japan in terms of the availability per worker of electrically driven machinery. This conclusion is based on the fact that the proportion of primary electric motors over total prime movers was much higher in Japan than in the US. So even if all the nonelectric primary movers in the Japanese manufacturing sector were used to generate electricity for secondary electric engines, which is most unlikely, the data for Japan presented in figure 6 could at most be increased by two thirds in the 1920s and by half in the 1930s. It should be noticed that these are exactly the increase rates that 
should be applied to the US data in figure 6 to account for the secondary electric capacity effectively recorded in the US industrial censuses.

Figure 6 seems to support David and Wright's suggestion of a US productivity and TFP leaping forward on the basis of much higher electrification levels in the manufacturing processes. As we noted before, capacity per worker measures can be a misleading indicator. A better way to assess the comparative contribution of the electrification of manufacturing processes to the growth of labour productivity and ultimately of TFP, is to use measures of electricity consumption per worker in the manufacturing sector. The total electricity consumed by the US manufacturing sector in $\boldsymbol{G W h}$ was as follows:

Table 8: Total electricity consumed by the US manufacturing sector ${ }^{11}$

\begin{tabular}{llll}
\hline \hline YEAR & $\boldsymbol{G W H}$ & YEAR & $\boldsymbol{G W H}$ \\
\hline \hline 1902 & 1,300 & 1927 & 51,012 \\
1907 & 5,100 & 1929 & 55,122 \\
1912 & 9,250 & 1935 & 56,706 \\
1917 & 20,750 & 1939 & 70,518 \\
1920 & 26,913 & 1947 & 140,947 \\
1923 & 32,585 & 1954 & 247,666 \\
1925 & 39,725 & 1958 & 318,059 \\
\hline \hline
\end{tabular}

From this and from the data on employment in the manufacturing sector (Kendrick, 1961) we have obtained the observations on the electricity consumed per employee in the US manufacturing sector that appear in figure 7.

We have estimated a similar series for the total electricity consumed per employee in the UK manufacturing sector. The methodology has been as follows. We took the 1930, 1935, and 1948 industrial production census data on the consumption of purchased electricity by the manufacturing sector in $\boldsymbol{G W h}$ and compared them with the data for the same years of the sales of electricity to industry (Ministry of Power, Statistical Digest 1967, Table 85, p 140). We observed that with time the consumption by the manufacturing sector accounted for an increasing share of the total sales of electricity to industry. We assumed that the rate of increase of the ratio of consumption to sales was constant between 1918 and 1935, and between 1935 and 1948. Using this assumption and using the dynamic implicit in the sales data, we recalculated a series of the consumption of purchased electricity by the manufacturing sector for the years $1920-1948$ which is consistent with the census observations. This is reported in table 9, column $\boldsymbol{k}$.

${ }^{11}$ Du Boff 1979 [but 1964], table 22, p. 84. Includes self-generated and purchased electricity. 
Table 9: Consumption of electricity in Great Britain's manufacturing sector.

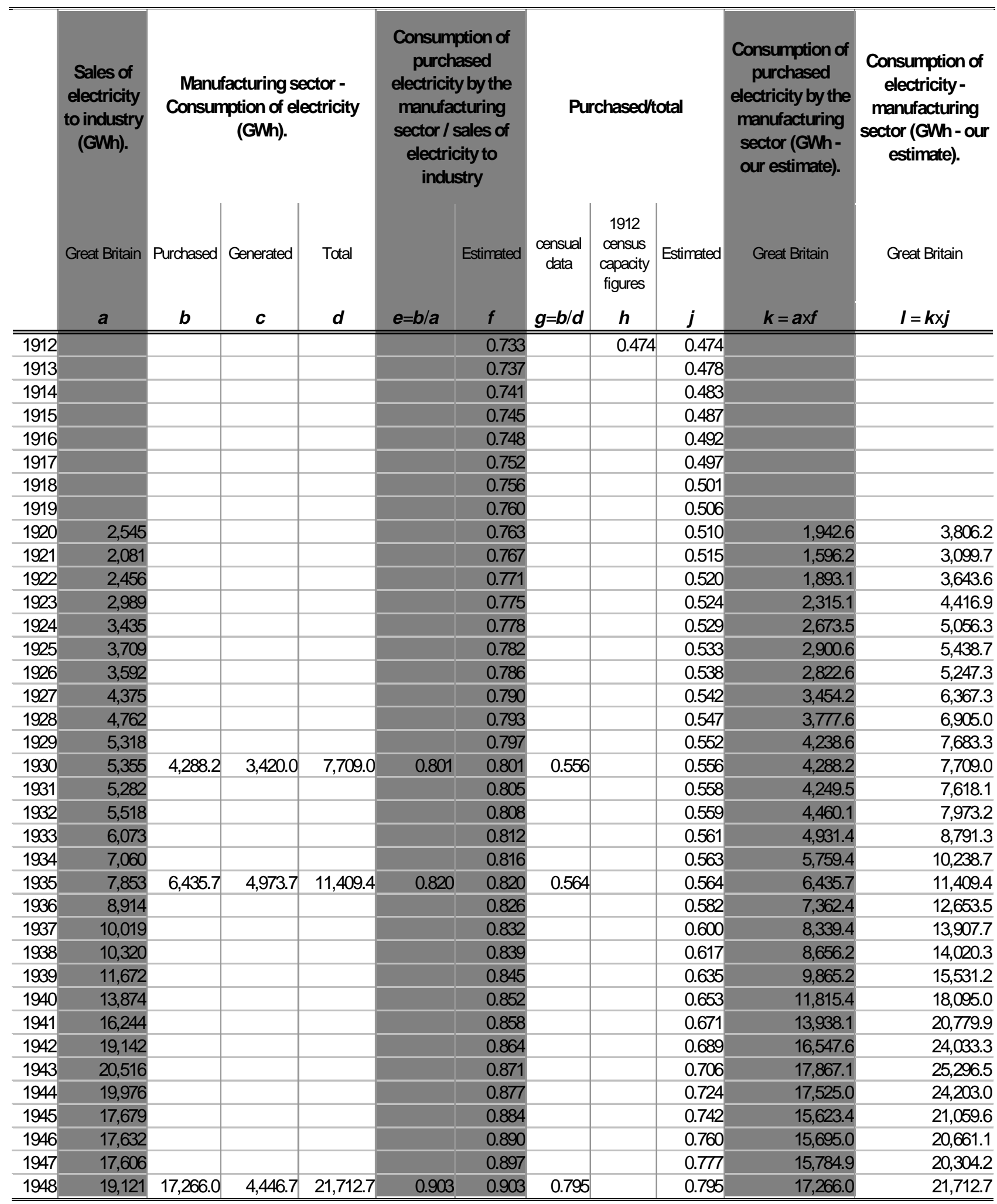

Sources: $\boldsymbol{a}$ Ministry of Power, Statistical Digest 1967, Table 85, p 140; $\boldsymbol{b}, \boldsymbol{c}$, and $\boldsymbol{d}$ Board of Trade, Business Statistics Office, Census of Production: Final Report, (censuses of 1930, 1935, 1948 and 1951); $\boldsymbol{h}$ Board of Trade, Business Statistics Office, Census of Production: Final Report, (1924 census). 
We then calculated the ratio between the census data for the consumption of purchased electricity by the manufacturing sector and the census data for the total consumption of electricity by the manufacturing sector. We then assumed that the rate of increase of this ratio was constant between census observations. We also assumed that the data from the 1912 census of production on the capacity of electric motors in the manufacturing sector driven by purchased electricity as a proportion of the capacity of all the electric motors in the manufacturing sector reflected the ratio between the purchases of electricity and the total consumption of electricity in the manufacturing sector in the same year. Under this assumption we were able to extend backward to 1912 the series for the ratio between consumption of purchased electricity and the total consumption of electricity. The resulting series is in table 9 , column $\boldsymbol{j}$. Using this series, and the estimated series for the consumption of purchased electricity by the manufacturing sector, we were able to construct a series for the consumption of electricity in the manufacturing sector for Great Britain (table 9, last column).

Having estimated the consumption of electricity by the manufacturing sector, and combining it with census data on employment and with Broadberry's index for employment in the manufacturing sector (Broadberry 1997, Table A3.1(a), pp. 43 44), we were able to construct a series for electricity consumption in the British manufacturing sector per employee (purchased and self-generated - in $\boldsymbol{K W h}$ ).

A similar indicator was calculated for Germany on data on industrial consumption of electricity published in the Statistical Yearbook of 1925, and 1932, and in the Statistical Handbook published in 1949. These figures were combined with employment data from Hoffmann 1965. The basic assumption adopted was that the proportion of electricity self-consumed by the utilities, the proportion of electricity sold by industry to the utilities, and the proportion of electricity consumed by the mining industry remained constant at the 1930 levels. A direct comparison of the consumption of electricity per employee in the manufacturing sector in the three countries is presented in figure 7.

This figure confirms the picture obtained from electric capacity data, and would seem to suggest that the UK's and Germany's manufacturing sectors relied much less than the their US counterpart on electricity. Figures 6 and 7 taken together confirm that the adoption of electrical technologies in production was markedly delayed in the UK, Germany and Japan as compared to the US. ${ }^{12}$

\footnotetext{
${ }^{12}$ It should be noted that the series for Great Britain in figure 6 might be slightly underestimated for the years prior to 1930. This is to do with the fact that the data of the 1912 census of production on electric motors driven by purchased electricity are incomplete and according to the census compilers are likely to overestimate the electric motors driven by purchased electricity. This would have the effect of underestimating the total electricity consumed by the manufacturing sector. On the other hand the calculations for the years 1931, 1932, 1933, and 1934 are likely to be slightly overestimated. This is so because the data on employment are obtained on the basis of the census data of 1935 which only includes companies with more than ten employees for the entire UK, while
} 
Moreover, the vast disparity in available electric capacity and consumption between the US manufacturing system and those of the other three countries increased throughout the interwar period in absolute terms. At the same time the electricity consumed by each employee in the US manufacturing sector remained three times as high as that consumed by his/her British or German counterpart for much of the period, and fell below this threshold only in the last part of the 1930s.

Figure 7: Consumption of electricity per employee in the manufacturing sector.

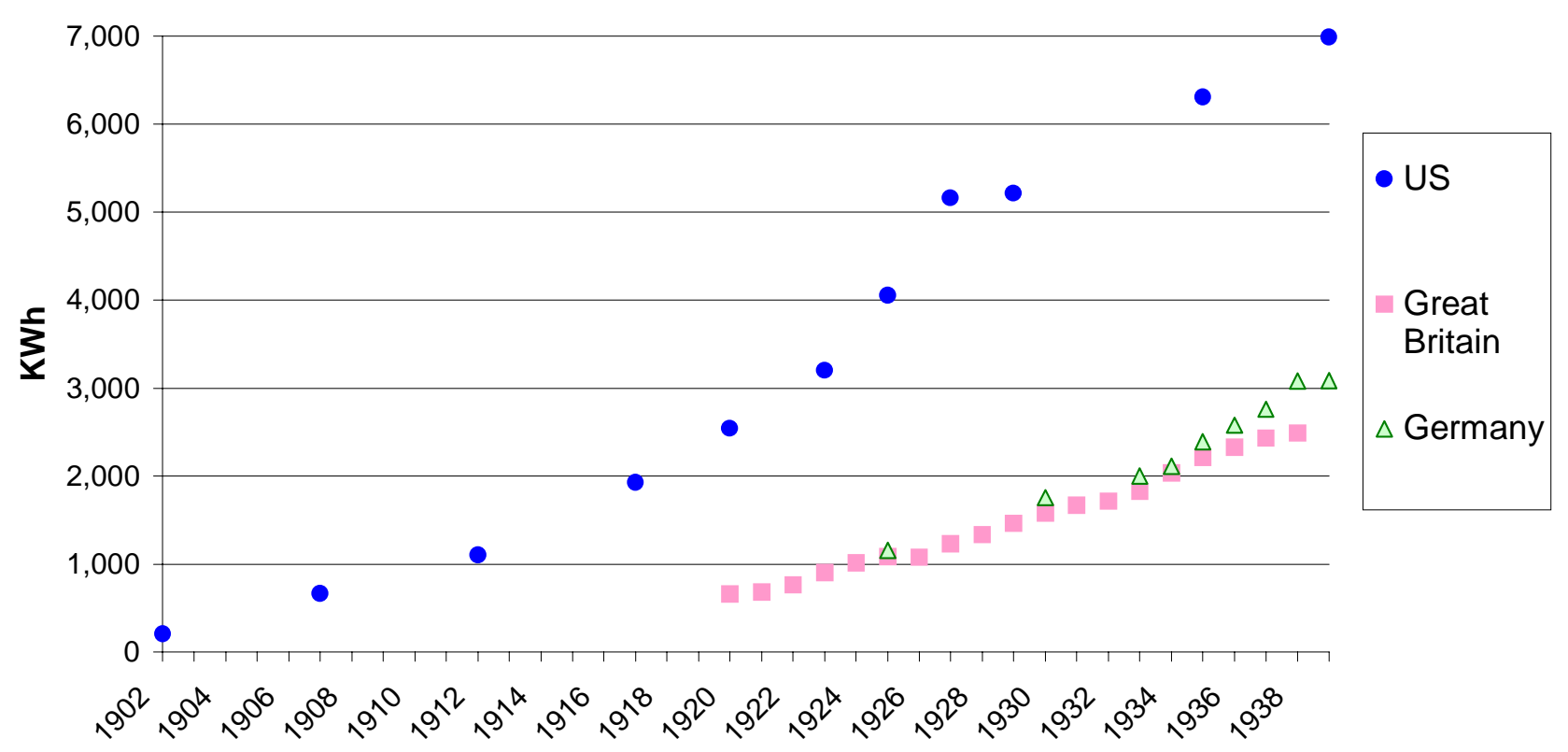

\section{Sources.}

Employment: US - Kendrick 1961, Table D-II, pp. 465 - 466 and Table D-VII p. 488; UK Business Statistics Office, Census of Production: Final Report, (censuses of 1930, 1935, 1948 and 1951) and Broadberry 1997, Table A3.1(a), pp. 43 - 44; Germany - Hoffmann 1965, Tab. 15, pp. 198 - 199;

Electricity consumption: US - Du Boff 1979 [but 1964], table 22, p. 84; UK - see table 9; Germany - Statististische Reichsamt, Statistisches Jahrbuch des Deutschen Reiches, Berlin (1928 edn. pp. 124-125; 1932 edn. pp. 114 - 115); Länderrat des Amerikanischen Besatzungsgebiets, Statistisches Handbuch von Deutschland 1928 - 1944, Munich 1949, pp. 336 - 337.

\section{CONCLUDing REMARKS}

The trends analysed here suggest that modern economic growth received a

the data for electricity consumption in these years are partially based on data from the 1930 census which extends the coverage to factories with more than 5 employees in Northern Ireland. The authors are convinced that these biases are unlikely to account for more than a few percentage points of the estimated figures. 
significant boost during the interwar period. Our main aim in this paper has been to evaluate whether electricity diffusion is associated with a trend acceleration in labour productivity $^{13}$. The results presented in this paper suggest that a major surge in US labour productivity growth was observed before the mid-1920s, although the new higher growth rates were sustained after this date once we control for cyclical variations. We consider the comparative evidence of America, Britain, Germany, and Japan as a way of testing the role of electricity diffusion in this process. The data analysed suggest that the diffusion of electricity in the manufacturing sector was more rapid in the US than in the other major industrial countries. The position of Britain and Germany in 1925 - in terms of the consumption of electricity per worker in manufacturing - was comparable to the US situation in 1912. As noted by David (1990) we observe long lags between the diffusion of this technology and effects on productivity growth. We have argued that the effect on labour productivity acceleration is observed after c.1906. The comparative evidence is consistent with the emphasis on electricity diffusion. Once Britain and Germany had invested enough in the new technology a productivity surge is observed in the late $1920 \mathrm{~s}^{14}$ By 1938 the extent of electricity diffusion in Britain and Germany was comparable to that of America in the early 1920s. Given that the diffusion path of Britain and Germany lagged the American path by 10-15 years we would expect the productivity gains to be significantly delayed. The manufacturing labour productivity trends suggest that most of the trend acceleration in the UK is a 1930s phenomenon. The evidence of a link between episodic growth in labour productivity and electricity diffusion in the manufacturing sector is more mixed for Germany. Here we do not observe labour productivity trend acceleration in the inter-war period. At most we can conclude that the effects of a lagged diffusion of electricity in the German manufacturing sector could have contributed to the high growth rates of labour productivity in this sector achieved notwithstanding the persistent effects of a lost European conflict, of hyperinflation, and of a gruelling economic depression in the early 1930s. Comparing the diffusion of electricity in Japan's manufacturing sector relative to Britain and America suggests that in terms of electricity capacity from electric motors per employee, Japan's position in 1929 was comparable to that of Britain in 1924 and America in 1918. A further phase of diffusion was observed in the 1930s. As with the UK the major productivity gains were delayed until the 1930s when this technology became generalised enough to affect the production methods of the whole sector.

These comparisons suggest that electricity diffusion in the manufacturing

\footnotetext{
${ }^{13}$ In focusing on these technological aspects of economic growth we need to emphasize that we are not dismissing demand side aspects. For example, the adverse macroeconomic conditions in Britain and Japan during the 1920s may have had an effect via determining the pace of diffusion of the new technology.

${ }^{14}$ The diffusion of electricity in the British manufacturing sector increased further in the 1930s thanks to the beneficial effects that the construction of the National Grid had on electric power prices and on the standardisation of supply.
} 
sectors of these three countries resulted in significant effects on the growth rate of labour productivity. The lags in the path of labour productivity growth are consistent with the diffusion path of the technology. The USA saw an earlier and more extensive diffusion of electricity use in the production methods of the manufacturing sector that had an observable effect on the trend growth rate of labour productivity during WWI and the 1920s. For Britain and Japan these effects were delayed until the end of the 1920s and the 1930s.

In conclusion, in the first half of the twentieth century the US, Japan, and the UK witnessed a transition from more extensive to intensive growth, based on productivity gains in the manufacturing sector. The trends in labour productivity growth in German manufacturing stand out as a special case. Our expectation is that Germany would have looked similar to Britain and Japan had it not been for the special circumstances Germany faced in the interwar period. The evidence of improved technological potential has to be seen as being counterbalanced by autarky, a regulated production, consumption and investment structure and regulated incentive structures. The four cases taken together indicate that the diffusion of electricity, whilst possibly a necessary condition for productivity trend acceleration in this period, was by no means a sufficient condition in the presence of structural distortions and/or adverse macroeconomic conditions.

The evidence on the effect of the timing of electricity diffusion is more definite. It demonstrates that the delay accumulated by the mid-twenties by Japan, Germany, and the UK in comparison with the US was of around ten to fifteen years. Accordingly, while the surge in the growth rates of labour productivity occurred in the US in the period from 1906 to 1925, this happened in the other three countries only from the mid-1920s onwards. The fact that the gap in electricity diffusion was to remain a structural difference between the US and the leading European economies well beyond the period investigated here, may prove of some relevance in explaining the long standing feature of much higher labour productivity in manufacturing in the US than on the old continent.

This paper confirms that electricity diffusion can persuasively explain the generalised growth in labour productivity in manufacturing in the industrialised world in the 1920s and 1930s. In other words, a technological/structural explanation can successfully be advocated in order to account for the upward shift in the trend of labour productivity growth in the interwar period in three of the four countries examined. As for Germany, the timing of electricity diffusion is consistent with the return to high labour productivity in the late 1920s and in the 1930s, even though this labour productivity surge did not constitute an upward shift in the productivity long-term growth trend. Our analysis establishes the existence of a marked correlation between electricity diffusion and labour productivity growth. This can be reasonably construed as evidence of a strong positive causal relationship between the two.

In underlining the evidence of this strong positive relationship between electricity diffusion and labour productivity growth we do not intend to dismiss the 
relevance of other factors that might have contributed to the observed increases in labour productivity in the manufacturing sector of the countries examined. Factors such as improved human capital and or qualitative changes to the stock of capital are likely to have contributed somehow to the growth of labour productivity in the period of electricity diffusion. This paper only confirms the likely link between electricity diffusion and a strong surge in labour productivity in the manufacturing sector.

Moreover, the fact that the diffusion of electricity affected TFP primarily by increasing labour productivity in the manufacturing sector has profound implications when it comes to the issue of economic convergence. If the acceleration in economic performance in this period is primarily related to the introduction of new manufacturing technologies, then the relative size of the manufacturing sector will determine the overall effect of the introduction of these technologies on the economy. This suggests that the benefits of electricity diffusion were greater where there was already a high degree of industrialisation. It follows that the diffusion of electricity produced an increase in economic divergence between industrialised and industrialising countries. On the other hand, the data we present on the diffusion of electricity per worker in the US and Japan does not support the suggestion often made in the literature that electricity diffusion was comparatively easier in late industrialising countries. Technological path dependence and inertia might have delayed the electrification of US production until the 1920s (David and Wright 1999b, p. 23) but this effect does not show in a comparative perspective. Nor other Gerschenkronian advantages of backwardness favouring electricity diffusion seem to have been dominant in international comparison. For example it is said that the specific characteristics of the dynamo revolution (divisibility of the source of power, modularity, ease of operation etc.) favoured the direct substitution of manpower with electricity in the smaller artisan establishments (see Hannah 1979, p. 172 for the UK, and Minami 1987 for Japan). This meant that take-up levels of electrical technologies in follower countries where the manufacturing sector was largely constituted of small industrial units should have been greater than in more industrialised countries. And yet, in Japan, an industrialising country with a large number small-sized artisan firms, the level of penetration of electric technologies in the manufacturing sector remained substantially lower than that of the US throughout the interwar period. It has also been suggested that the increase in TFP might also be associated with the diffusion of electrically driven consumer durables. In this case the effect of the diffusion of electricity goes in the direction of increasing TFP divergence between the US, which had already a large market for consumer goods, and its main competitors. It should be noted that this divergence-enhancing effect is more to do with the peculiar situation of a high US absolute real wage level, than to the openness to technological innovation of US entrepreneurs ${ }^{15}$.

\footnotetext{
15 There are two aspects to the issue of US primacy in electricity diffusion. Firstly, the reason that US took an early lead. This should be explained on the basis of the relative cheapness of power due to dissimilar natural resource endowments, but also on the basis of the fact that the US abandoned
} 
Electricity diffusion cannot be treated as exogenous. Electricity was a generalpurpose technology i.e. a technology that could be easily and cheaply applied to a vast array of production processes. Its clearly understood and relatively uncomplicated principles and its ease of application to many uses and processes made it a prime candidate for general adoption in industrialised and industrialising countries. The US managed to use more electricity per worker earlier than other countries and was able to sustain this lead even when other countries were making significant strides in diffusion in the 1930s. Allowing electricity to be treated as exogenous would imply that there was entrepreneurial failure on a massive scale in the industrialised word outside the US. This is clearly an untenable position, and the higher US take-up rate of electric technologies has to be explained differently. The reason for the US lead in the use of electricity per worker is likely to be related to the rich resource endowment of the US. In particular the comparatively high penetration of electricity in the US manufacturing sector is likely to be the direct result of the relative cheapness of electricity in that country. This in turn was due to the relative cheapness of thermal generation in the US, owing to the low price of the natural resources (oil and coal) employed.

This hypothesis can be easily tested using census data for Britain and the US. In 1935 the British manufacturing sector was reported to have bought 7,100 $\boldsymbol{G W h}$ of electric energy at a cost of $£ 23,570,000$. This meant that the average cost of a $\boldsymbol{K} \boldsymbol{W h}$ for the British manufacturer was $£ 0.00332$ or $0.80 d$ of the time. ${ }^{16}$ At the prevailing exchange rate of $\$ 4.971$ per pound (Mitchell 1988, p. 703) in 1935 the price of a $\boldsymbol{K} \boldsymbol{W h}$ bought by the average British manufacturer was equal to $\$ 0.0165$. As a term of comparison we observe that in 1929 and 1937 the average price paid by US manufacturers to acquire a $\boldsymbol{K} \boldsymbol{W h}$ was $\$ 0.0127$, and $\$ 0.0102$ respectively. ${ }^{17}$ This suggests that the price of electricity paid by British manufacturers in 1935 was ca. 50 per cent higher than that paid by their US counterparts. Given the strict correlation

regulatory constraints on electricity supply earlier than other countries (David and Wright 2002, Hannah 1979). This allowed the formation of regional networks capable to maximise the scale economies typical of electricity generation and therefore to reduce the cost of electricity. Secondly, there is the issue of why US manufacturing continued to be much more energy intensive than its European and Japanese counterparts. Here, again price differentials were at work, but it is unlikely that the regulatory environment in which electrical utilities operated played a great role in determining this price differential beyond the early 1930s in the UK. Moreover it is unclear whether regulatory constraints on the supply side played a role in the timing and extent of electricity diffusion in Germany and Japan.

${ }^{16}$ Our calculation on the basis of the individual industry cost returns of the 1935 UK census of production. The original figures refer to electricity purchased and used, including electricity generated in other works under the same ownership.

${ }^{17}$ Our calculations on data from the 1939 US census of manufactures. Note that the data on the US $\boldsymbol{K W h}$ cost in manufacturing given by Broadberry 1997 in Table 7.5 p. 101 is mistakenly expressed in pence, while it should be expressed in US cents (see Melman 1956, p. 206). Also note that the Melman's calculations based on the electricity price paid by large manufacturers are very close to our calculations based on the more comprehensive census returns in the US case, and are substantially lower for the UK $(0.69 d$ as opposed to our $0.80 d)$. 
between the cost of electricity and the cost of its direct substitutes (coal, oil, etc.), this price differential indicates that sources of power in general were considerably cheaper in the US than in the UK. In turn, this should be a strong indication of the energy intensive nature of production in the US, provided that one takes the not entirely unreasonable view that other production inputs such as capital and labour were not substantially cheaper in the US than in the UK. Indeed, there is strong evidence to suggest that the cost of labour relative to the cost of electric energy in manufacturing was at least twice as high in the US than in the UK, Germany and Japan for the duration of the second quarter of the twentieth century (Broadberry 1997, Table 7.5, p. 101 and Melman 1956, p. 206 and 213). We can only agree with Broadberry's remarks on the likely continuation of the effect of energy endowments on comparative labour productivity in the rest of the century (Broadberry 1997, p. 102). 


\section{APPENDIX. KALMAN FILTER STRUCTURAL MODEL OF TIME SERIES DECOMPOSITION}

In order to shed some light on the empirical features of trend movements and we use the following Kalman filter structural model of time series decomposition (Harvey, 1985, 1989):

$$
y_{t}=\mu_{t}+\psi_{t}+\varepsilon_{t}
$$

where

$$
\begin{aligned}
& \mu_{t}=\mu_{t-1}+\beta_{t-1}+\xi_{t-1} \\
& \beta_{t}=\beta_{t-1}+v_{t}
\end{aligned}
$$

$$
\psi_{t}=(1-\rho \cos \lambda L) \omega_{t}+(\rho \sin \lambda L) \omega_{t}^{*} /\left(1-2 \rho \cos \lambda L+\rho^{2} L^{2}\right)
$$

where $\mu_{t}$ stands for the trend component of $y_{t} ; \xi_{t}$ allows the trend to shift up and down; $v_{t}$ accounts for shocks to the slope, $\beta_{t} ; \psi_{t}$ captures the cyclical regularities in $y_{t} ; L$ represents the lag operator; $\omega_{t}$ represents the shocks to the cyclical component; $\varepsilon_{t}$ accounts for short-term erratic movements and possible measurement errors in $y_{t}$. $\varepsilon_{t}, \xi_{t}, v_{t}$ and $\omega_{t}$ are assumed to be mutually independent white noise processes, with $\omega_{t}^{*}$ arising by construction under the constraint that $\sigma(\omega)=\sigma\left(\omega^{*}\right) ; \lambda$ is the frequency of the cycle and $\rho$ is the damping factor. The existence of short (high frequency) and long (low frequency) cycles makes it necessary to model a number of cycles simultaneously.

Maximum likelihood estimates of the unknown parameters $\sigma_{(\xi)}, \sigma_{(\mathrm{v})}, \sigma_{(\varepsilon)}, \sigma_{(\omega)}$ and $\rho$ can be obtained by the Kalman filter algorithm. The latter implements a set of recursive equations from given initial values of the parameters, which are successively updated in the light of every new observation (Harvey, 1989).

Although such a time-series structural model has the limitation of imposing a specific structure upon the data, it has a number of important advantages. First, the model nests two extreme specifications for the trend; the deterministic or trendstationary model and the stochastic trend or 'difference stationary' model. Moreover, since the model allows $\xi$ and $\mathrm{v}$ to vary over time, this allows for the possibility that the trend may be deterministic over sub-periods, while possessing a significant stochastic component over the entire period. The model ultimately lets the data determine the shape of the trend and thus makes it possible to extract the cyclical component under a wide variety of possible trend specifications. The main advantage of this framework is that we can focus both on the nature of trend variations and the patterns of low frequency fluctuations jointly and independent of sample selection biases. 


\section{BIBLIOGRAPHY}

Abramovitz, M. (1968), 'The Passing of the Kuznets Cycle', Economica, V. 34, pp. $349-67$.

Abramovitz, M. (1961), 'The Nature and Significance of Kuznets Cycles', Economic Development and Cultural Change, V. 9, supplement, pp. $225-248$.

Abramovitz, M., David, P. A. (2000), 'American macroeconomic growth in the era of knowledge-based progress: the long-run perspective', in Stanley L. Engerman and Robert E. Gallman (eds.), The Cambridge economic history of the United States. Volume III. The Twentieth Century, Cambridge University Press, p. $1-92$.

Broadberry, S. N. (1997), The productivity race. British manufacturing in international perspective, 1850 - 1990, Cambridge University Press 1997.

David, P. A., Wright, G. (1999a), 'General purpose technologies and surges in productivity: Historical reflections on the future of the ICT revolution', in Discussion Papers in Economic and Social History, No. 31.

David, P. A., Wright, G. (1999b), 'Early Twentieth century productivity growth dynamics: an inquiry in the economic history of "our ignorance", in Discussion Papers in Economic and Social History, No. 33.

David, P.A and Wright, G. (forthcoming 2002), 'General Purpose Technologies and Surges in Productivity: Historical Reflections on the Future of the ICT Revolution', in P.A. David and M. Thomas (eds.), Economic Future in Historical Perspective, Chapter 4, Oxford University Press for the British Academy.

Du Boff, R. B. (1967), 'The introduction of electric power in American manufacturing', Review of Economic History, V. 20, No. 3, pp. 509 - 518.

Du Boff, R. B. (1979 [but originally 1964]), Electric power in American manufacturing, 1889-1958, Arno Press.

Germany, Statististische Reichsamt (1928 and 1932), Statistisches Jahrbuch des Deutschen Reiches, Berlin.

Germany, Länderrat des Amerikanischen Besatzungsgebiets (1949), Statistisches Handbuch von Deutschland 1928 - 1944, Munich.

Hannah, L. (1979), Electricity before nationalisation. A study of the development of the electricity supply industry in Britain to 1948, Macmillan.

Hoffmann, W. G. (1965), Das wachstum der Deutschen wirtschaft seit der mitte des 19. Jahrhunderts, Springer-Verlag.

Kendrick, J. W. (1961), Productivity trends in the United States, Princeton University Press.

Melman, S. (1956), Dynamic factors in industrial productivity, Basil Blackwell.

Minami, R. (1965), Railroads and electric utilities, V. 12 of Ohkawa, K., Shinoara, M., Umemura, M., (eds.), Estimates of long-term economic statistics of Japan 
since 1868, Toyo Keizai Shinposha, Table 27, p. 223.

Minami, R. (1977), 'Mechanical power in the industrialization of Japan', in Journal of Economic History, V. 37, No. 4, pp. 935 - 958.

Minami, R. (1987), Power revolution in the industrialization of Japan: 1885 - 1940, Kinokunia Company Ltd.

Mitchell, B. R. (1998), International historical statistics. Europe 1750 - 1993 (4th edn.), Macmillan, pp. 562-565.

Mitchell, B. R. (1998), International Historical statistics. The Americas 1750 - 1993 (4th edn.), Macmillan, p. 405 and p. 408.

Mitchell, B. R. (1988), British historical statistics, Cambridge University Press.

Ohkawa, K., Takamatsu, N., Yamamoto, Y. (1974), National income, V. 1 of M. Ohkawa, K., Shinohara, M., Unemura, M. (eds.), Estimates of long-term statistics of Japan since 1868, Toyo Keizai Shinposha.

Shinohara, M. (1972), Mining and Manufacturing, V. 10 of Ohkawa, K., Shinohara, M., Umemura, M., (eds.), Estimates of long-term economic statistics of Japan since 1868, Toyo Keizai Shinposha, Table 2, pp. 144 - 147.

Umemura, M., Akasaka,K., Minami, R., Takamatsu, N., Arai, K., Itoh, S. (1988), Manpower, V. 2 of Ohkawa, K., Shinohara, M., Umemura, M. (eds.), Estimates of long-term statistics of Japan since 1868, Toyo Keizai Shinposha.

UK Board of Trade; Business Statistics office, Census of Production: Final Report, (censuses 1924, 1930, 1948, 1951), HMSO.

UK Ministry of Power (1968), Statistical Digest 1967, HMSO.

UK Ministry of Power (1969), Digest of energy statistics 1968 and 1969, HMSO.

US Bureau of the Census (1975a), Historical statistics of the United States. Colonial Times to 1970. Bicentennial edition. Part 1, US GPO, p. 137.

US Bureau of the Census (1975b), Historical statistics of the United States. Colonial times to 1970. Part 2, US GPO, 1975, p. 681.

US Department of Commerce, Bureau of the Census (1942), Sixteenth Census of the United States: 1940. Manufactures 1939. Volume I. Statistics by Subject, US GPO, Table 4, p. 20; Table 5 pp. 22-40; and Table 1, p. 337.

US Department of Commerce, Bureau of the Census (1933), Fifteenth Census of the United States. Manufactures 1929. Volume I. General Report. Statistics by Subject, US GPO, 1933, Table 3, p. 16. 